different in their chemical and bacteriological content and treatment methods so limited by technical and financial resources that it is not to be expected that the high standard reached in certain localities will immediately become universally applicable. The standards suggested represent rather the minimum requirements to which a public water supply should conform and in the absence of which it cannot be considered entirely free from risk. This is in itself a great advance and will be of inestimable value to health and water authorities in those parts of the world where at present water supplies do not attain the desired criteria.

In the International Standards for Drinking Water*, recently published by the World Health Organization, a chapter is devoted to each of the subjects of bacteriological, chemical and physical, biological and radiological requirements. This is followed by a section in which are indicated matters requiring further researeh in each of these fields. In some cases it might appear that the subject suggested for study has already been adequately investigated, but it can do no harm for some old ground to be re-covered if the results are made more widely known and a re-assessment of some cherished beliefs may prove salutary.

In a rapidly expanding subject it is inevitable that a publication of this kind should be somewhat behind the latest information. This applies particularly to the chapter on radiological requirements, which seems unduly brief. There is no mention of the part * World Health Organization. International Standards for Drinking
Water. Pp. 152. (Geneva : World Health Organization : Jondon : H.M. Stationery Office, 1958.) 12 Swiss franes; 20 s. ; 4 dollars. played by the naturally occurring isotope, potassium-40, in contributing towards the total radioactivity in water, although it is only fair to say that for further information the reader is referred to the recommendations of the International Commission on Radiological Protection.

Any consideration of standards, particularly in the bacteriological or chemical spheres, must take some account of the methods whereby these are measured, and the second, and larger, portion of the book is devoted to a series of approved methods for bacteriological, chemical and biological examination of water. Starting with a list of required materials, each procedure is explained step by step in simple language which is a model of clarity. Not the least important sections are those detailing the particulars to be supplied with samples and the recommendations on the frequency of sampling. Tables are given for the computation of the most probable number index with upper and lower confidence levels. In the chemical section, lists with permissible levels are provided not only of those naturally occurring substances which may affect potability but also of toxic materials such as lead, arsenic, selenium, chromium and cyanide, with details of methods for their estimation.

If one may venture a further minor criticism of so valuable a work, it is that a comprehensive index might have increased its usefulness. As it is, the volume is an excellent example of what can be achieved by international co-operation and a milestone on the way to safe water supplies throughout the world.

\title{
THE WEIZMANN INSTITUTE OF SCIENCE
}

$\mathrm{T}$ THE report for 1956-57 of the Weizmann Institute of Science*, besides summarizing the scientific activities of the several departments and sections, includes a list of publications during the period and details of the scientific staff, as well as of the administrative and technical staff and supporting committees. It is introduced by a statement of policy for the future of the Institute by Mr. M. W. Weisgal, chairman of the Executive Council, which expresses grave concern regarding the financial position of the Institute. Anticipated ineome for the four years April 1956-March 1960 fell short of estimated requirements by about 6 million dollars, and the measures proposed by Mr. Weisgal include launching a campaign for an Endowment Fund of 25 million dollars.

Fundamental research in the Department of Applied Mathematics was directed mainly to the solution of mathematical problems in statistical mechanies, wave propagation, geophysies, hydrodynamics and X-ray crystallography. In nuclear physics, besides investigation on nuclear models, some work on reactor physics was undertaken for the Israel Atomic Energy Commission. The Department of Isotope Research records progress in the production of stable isotopes, the use of stable and radioactive isotopes in studying the mechanism of inorganic and organic reactions and in various

* Weizmann Institute of Science. Report 1956-1957, Pp. 190. (Rehovoth : Weizmann Institute of Science, 1958.) applications of natural and artifieial radioactivity. Investigations by the Department of Organic Chemistry embraced the structure of natural compounds, the chemistry of the sphingolipids, steroid and acetylene chemistry, syntheses in the terpene series, petroleum chemistry and applied spectroscopy.

Besides studies of polyelectrolytes, ineluding their biological aspects, in the Department of Polymer Research, gels, membranes and mechano-chemistry received attention, as well as polynitroethylene, polyvinyl bromide and polyvinylanthracene. The Department of X-ray Crystallography continued to investigate intra- and inter-molecular compression forces on molecular structure and to study the mechanism of solid-state reactions by combined X-ray crystallographic and physico-chemical methods, while work in the Department of Experimental Biology included such diverse fields as the biological mechanism of the induction of tumours, the metabolism of urethane in relation to its tumour-inducing activity, the mechanism of deciduoma formation and its relation to placental implantation of the ovum, immuno-genetics of tumour implantation, radiobiological aspects of tumour immunity, biochemical and endocrinological aspects of sugar metabolism and problems in human genetics and neuropharmacology. The Department of Biophysics continued to be concerned mainly with work on synthetic poly$\alpha$-amino-acids and their use in elucidating chemical and physical properties of proteins and natural 
polypeptides. In the Department of Electronics a more generalized theory of rotational magnetic processes was formulated and several magnetic measuring devices were built. The main effort of the Infra-red Section was on the construction of a large vacuum spectrometer-refractometer for use in the near infrared region; the Section of Photochemistry and
Spectroscopy investigated chemical processes involved in photochromic phenomena and the influence of ionizing radiation and high-energy particles on phototropic and photochromic compounds; and the Section of Plant Genetics was concerned with the mechanism of the development of sex in plants.

\section{THE BRITISH FLORA DURING 1958}

$\mathrm{T}$ HE publication during 1958 of a new and authoritative list of vascular plants accepted as established members of the British flora ${ }^{1}$, and including some 2,895 species and 538 hybrids, is a timely reminder of the relative thoroughness with which the flora has been investigated. The additions which continue to be made annually are evidence that native plants can be long overlooked even on the best-worked ground, and that new aliens continue to find ecological niches where they can establish themselves in competition with species already present. Comparison of the new list with the last full-scale list of the British flora issued in 1928 shows that since then there has been a net addition of some 370 established species. That botanists can add an average of 12 such species annually (and this takes no account of casuals) shows how rapidly the known British flora is changing.

At the annual exhibition meeting of the Botanical Society of the British Isles, held in the lecture hall of the Royal Horticultural Society on November 29, the exhibits included several interesting additions to the British list. One of these was Juncus subulatus from the salt-marsh at Berrow, Somerset, which was shown by E. W. Davies and J. Willis (Bristol). This salt-marsh was formed about 1910, and its development has been under observation since 1921 and has been the subject of several ecological studies ${ }^{2-5}$. Two large and flourishing colonies of the rush are spreading vegetatively by vigorous growth of the rhizomes in the zone of Scirpus maritimus - the latter appeared about 1926 and increased extremely rapidly during the next two years ${ }^{3}$. Juncus subulatus is widespread in the salt-marshes of the Mediterranean coast, and Berrow is apparently its most northerly station. Here it is reproducing from seed as well as vegetatively. Now that attention has been directed to the plant, it may well be found elsewhere on the coast of Britain-it can easily be passed over as $J$. maritimus or perhaps as a luxuriant $J$. gerardi.

Another rush added to the British list was shown by N. D. Simpson and S. M. Walters (Cambridge). This is $J$. bufonius subsp. foliosus, also a native of the Mediterranean countries, which was found in two places in west Cork and one in south Kerry. In the field it is strikingly different from the usual $J$. bufonius, having flowers often more than $1 \mathrm{~cm}$. in diameter with a dark stripe bordering the greenish midrib of the perianth segments and wider leaves which are not setaceous. The seeds also differ, but the Irish material was not sufficiently ripe to check this character.

An undescribed Sorbus from the Avon Gorge was shown by E. F. Warburg (Oxford). This has previously been confused with S. hungarica. Dr. Warburg also exhibited two forms of Sorbus pseudofennica from Arran which are probably distinct apomictic clones. Two well-established aliens were exhibited by H. J. M.
Bowen (Harwell). Geranium pilosum, a native of New Zealand, was found in Alderney, and Hydrocotyle moschata, also from New Zealand, is freely naturalized in Valencia Island, Kerry.

Several very rare plants were found in new localities during the year. One of the most interesting of these is Lythrum hyssopifolia, which was found in quantity at Whittlesford, Cambridgeshire, by Mrs. G. Crompton, and which was the subject of an exhibit by D. E. Coombe, F. H. Perring and S. M. Walters (Cambridge). This is at present known to oceur regularly only in Jersey, and it has been found in only four other localities in the present century; but revision of the records shows that there has also been some confusion with an allied species sometimes found as a casual. Lythrum hyssopifolia is native in central and eastern England, growing in wet open communities. It seems likely that seed may remain viable for long periods and enable the plant to re-appear in favourable seasons. Fvidently the persistent wet conditions of 1958 suited it well.

The discovery of another new locality for an orchid, Spiranthes romanzoffiana, is also of special interest. This was found by Lough Corrib in Galway by a party collecting records for the Society's Maps Scheme, and a photograph was exhibited by Miss A. K. Harding and Mrs. B. H. S. Russell. The new locality represents a considerable extension of range from those previously recorded in the south and north of Ireland-it seems that this orehid is spreading into new and widely scattered habitats (including western Scotland and Devonshire). The first authentic inland record of Equisetum variegatum from the south of England was the subject of an oxhibit by E. F. Warburg (Oxford). This horsetail was found by E. G. Arthurs in an old quarry at Cothill, Berkshire; the nearest previously known station is at Weston-super-Mare.

An important new hybrid was shown by $P$. M. Benoit. This was between Euphorbia paralias and E. portlandica, with morphological characters convincingly intermediate between the two parents and fruits failing to complete their development. He found it in two places on the coast of Merionethshire. P. M. Benoit also exhibited an interesting series of synthesized hybrids of Stellaria. These included $S$. media $\times$ neglecta $(90$ per cent), S. pallida $\times$ neglecta $(50$ per cent), S. neglecta $\times$ pallida $(50$ per cent) and $S$. pallida $\times$ media $(23$ per cent). The percentages indicate the approximate proportions of sterile pollen grains. The following back-crosses were also shown : $S .($ pallida $\times$ neglecta $) \times$ neglecta, $S$. pallida $\times($ pallida $\times$ neglecta $), S .($ pallida $\times$ media $) \times$ media. J. A. Ratter (Liverpool) exhibited hybrids of Spergularia, and J. P. Savidge (Liverpool) showed specimens of the only naturally occurring hybrid population of Callitriche found during his investigation of the genus. This was from Hillerød, Denmark ; the pollen 